\title{
PASSING THE DVLC FIELD REGULATIONS FOLLOWING BILATERAL PAN-RETINAL PHOTOCOAGULATION IN DIABETICS
}

\author{
M. F. G. HULBERT and S. A. VERNON \\ Nottingham
}

\begin{abstract}
SUMMARY
Twenty-one diabetics who had had bilateral retinal panphotocoagulation preserving a visual acuity sufficient to pass the Driver and Vehicle Licensing Centre (DVLC) requirements were assessed with regard to their ability to satisfy the DVLC visual field requirements. Of the 19 patients treated with the laser alone, 17 met the requirements for a licence to drive a private vehicle.

The use of the Xenon photocoagulator and large total burn area following laser was found to be associated with an increased risk of DVLC field test failure.

Adequate PRP with 200 micron burns appeared to induce neovascular regression and be compatible with passing the DVLC field regulations in many patients.

Panphotocoagulation of patients with early proliferative retinopathy using 200 micron burns does not appear to jeopardise a driving licence.

Guidelines for laser treatment in diabetic retinopathy aimed at preserving the driving field are presented.
\end{abstract}

For the last 15-20 years, panretinal photocoagulation (PRP) has been the mainstay of treatment for diabetics with proliferative retinopathy. Many reports have shown its value in inducing neovascular regression and preserving visual acuity. ${ }^{1.2}$

Although Xenon arc was used in the early years, lasers are now preferred by most ophthalmologists. A standard treatment consists of up to 2000 argon burns at the 500 micron setting scattered over the peripheral retina with further photocoagulation where necessary. ${ }^{3}$ For the last five years it has been policy in our diabetic retinal clinic to use 200 micron burns for PRP in the initial treatment protocol as this size of burn is often easier for the patient to tolerate and for the operator to deliver.

Many patients receiving PRP to both eyes continue to drive maintaining a binocular acuity acceptable to the DVLC. This valuable asset is often necessary for their continued employment.

Correspondence to: Mr S. A. Vernon FRCS, FCOphth, Academic Unit of Ophthalmology. University Hospital, Nottingham, UK.
Diabetics should inform the DVLC following laser treatment to both eyes. They are then obliged to undertake a formal acuity and field test.

Reading a number plate at 25 yards equates to a binocular acuity of approximately $6 / 10 .^{4}$ The British field regulations require the patient to have a binocular field to a $4 \mathrm{~mm}$ target that spans $120^{\circ}$ horizontally by $40^{\circ}$ vertically. ${ }^{5}$ A person with normal vision will pass this on one eye alone.

Previous studies have confirmed that photocoagulation with burns of 500 micron diameter is associated with loss of peripheral visual field. ${ }^{6.7}$ Generalised constriction and isolated scotomas may occur, particularly if confluent burns are used to close new vessels directly. Loss of visual field in both eyes may prejudice the ability of an individual to pass the United Kingdom DVLC field regulations.

In order to define risk factors for failing the DVLC field regulations, we reviewed the notes of all patients who had bilateral PRP between July 1986 and June 1990.

\section{PATIENTS AND METHOD}

Patients with a binocular acuity of 6/9 or better had Goldmann fields performed. The field technician was unaware of the treatment the subject had received. Each eye was tested separately using kinetic and static targets. Static tests were performed at each intersection on the Goldmann chart within the $120^{\circ}$ by $40^{\circ}$ parameters determined by the DVLC.

A 'clear pass' was recorded if there were no points missed within the $120^{\circ}$ by $40^{\circ}$ zone which would result in a binocular scotoma. For example, a missed point in the field of one eye could be compensated by a point seen in the corresponding position in the field of the other eye.

It is recognised that the Visual Standards Committee advising the DVLC uses more detailed criteria to judge borderline cases. Therefore patients whose fields demonstrated constriction within the $120^{\circ}$ by $40^{\circ}$ parameters or whose fields contained binocular scotomas had their fields assessed by the Chairman of the Visual Standards Com- 
Table I. Treatment details of those patients who scored clear passes on the DVLC field test

\begin{tabular}{|c|c|c|c|c|c|}
\hline \multirow[b]{2}{*}{ Patient } & \multicolumn{3}{|c|}{ Disease severity } & \multicolumn{2}{|c|}{ Treatment } \\
\hline & NVD & NVE & Gliosis & Right eye & Left eye \\
\hline $\mathrm{L}$ & + & & & $\begin{array}{r}4344 \times 200 \mathrm{~m} \\
973 \times 500 \mathrm{~m}\end{array}$ & $\begin{array}{c}3164 \times 200 \mathrm{~m} \\
543 \times \mathrm{IL}\end{array}$ \\
\hline $\mathbf{M}$ & + & + & + & $3238 \times 300 \mathrm{~m}$ & $\begin{array}{r}2792 \times 200 \mathrm{~m} \\
150 \times 500 \mathrm{~m}\end{array}$ \\
\hline $\mathbf{N}$ & & + & & $\begin{array}{l}2509 \times 200 \mathrm{~m} \\
1500 \times 400 \mathrm{~m}\end{array}$ & $1045 \times 200 \mathrm{~m}$ \\
\hline $\mathrm{O}$ & & + & & $2854 \times 200 \mathrm{~m}$ & $\begin{array}{r}2571 \times 200 \mathrm{~m} \\
780 \times 300 \mathrm{~m}\end{array}$ \\
\hline$P$ & + & + & + & $5572 \times 200 \mathrm{~m}$ & $5012 \times 200 \mathrm{~m}$ \\
\hline $\mathrm{Q}$ & & + & & $3012 \times 200 \mathrm{~m}$ & $3983 \times 200 \mathrm{~m}$ \\
\hline $\mathrm{R}$ & & + & + & $\begin{array}{l}4977 \times 200 \mathrm{~m} \\
1995 \times 500 \mathrm{~m}\end{array}$ & $\begin{array}{r}470 \times 200 \mathrm{~m} \\
1470 \times 500 \mathrm{~m}\end{array}$ \\
\hline$S$ & + & + & & $\begin{array}{r}1918 \times 200 \mathrm{~m} \\
968 \times 400 \mathrm{~m} \\
950 \times 500 \mathrm{~m}\end{array}$ & $3250 \times 2-400 \mathrm{~m}$ \\
\hline $\mathrm{T}$ & & + & & $2571 \times 200 \mathrm{~m}$ & $3521 \times 200 \mathrm{~m}$ \\
\hline $\mathrm{U}$ & & + & & $1338 \times 200 \mathrm{~m}$ & $2037 \times 200 \mathrm{~m}$ \\
\hline
\end{tabular}

$\mathrm{m}=$ microns; $\mathrm{IL}=$ indirect laser.

mittee of the College of Ophthalmologists (CVSC). This assessment was performed without knowledge of the details of laser treatment performed.

\section{RESULTS}

In the four-year period, 31 patients with bilateral PRP were considered to have had stable retinopathy for a minimum of six months. Five were unavailable for analysis. Four had bilateral ischaemic maculopathy and failed on acuity, and one was demented. The remaining 21 patients had fields performed to DVLC standards.

Two patients treated with bilateral Xenon photocoagulation had severe field constriction and were clear failures. Of the 19 patients treated with the laser, 10 were clear passes (Table I). The average number of burns per eye in this group was 3475 . In total seven eyes from seven patients had clear passes on one eye alone. In $6 / 10$ cases no burns greater than 200 microns had been delivered to

Table II. Treatment details of those patients whose fields were referred to the Chairman of the Visual Standards Committee

\begin{tabular}{|c|c|c|c|c|c|}
\hline \multirow[b]{2}{*}{ Patient } & \multicolumn{3}{|c|}{ Disease severity } & \multicolumn{2}{|c|}{ Treatment } \\
\hline & NVD & NVE & Gliosis & Right eye & Left eye \\
\hline $\mathrm{C}$ & & & & $2565 \times 200 \mathrm{~m}$ & $2076 \times 200 \mathrm{~m}$ \\
\hline D & & + & & $\begin{array}{r}750 \times 200 \mathrm{~m} \\
1063 \times 500 \mathrm{~m}\end{array}$ & $\begin{array}{r}1144 \times 200 \mathrm{~m} \\
700 \times 300 \mathrm{~m} \\
481 \times 500 \mathrm{~m}\end{array}$ \\
\hline $\mathrm{E}$ & + & + & & $\begin{array}{l}1319 \times 200 \mathrm{~m} \\
4170 \times 500 \mathrm{~m}\end{array}$ & $\begin{array}{l}1184 \times 200 \mathrm{~m} \\
2267 \times 500 \mathrm{~m}\end{array}$ \\
\hline$F$ & + & + & & $\begin{array}{r}356 \times 200 \mathrm{~m} \\
1135 \times 300 \mathrm{~m} \\
505 \times 450 \mathrm{~m}\end{array}$ & $3165 \times 300 \mathrm{~m}$ \\
\hline G & + & + & + & $\begin{array}{l}1012 \times 350 \mathrm{~m} \\
1597 \times 500 \mathrm{~m}\end{array}$ & $\begin{aligned} 462 & \times 200(\mathrm{R}) \\
550 & \times 400 \mathrm{~m} \\
1967 & \times 500 \mathrm{~m}\end{aligned}$ \\
\hline $\mathrm{H}$ & & + & + & $\begin{array}{l}7167 \times 200 \mathrm{~m} \\
1500 \times 500 \mathrm{~m}\end{array}$ & $8485 \times 200 \mathrm{~m}$ \\
\hline I & + & + & & $\begin{array}{l}1606 \times 2-400 \mathrm{~m}(\mathrm{R}) \\
1034 \times 400 \mathrm{~m}\end{array}$ & $2045 \times 400 \mathrm{~m}(\mathrm{R})$ \\
\hline J & + & + & + & $4386 \times 200 \mathrm{~m}$ & $\begin{array}{l}2390 \times 200 \mathrm{~m} \\
1041 \times 500 \mathrm{~m}\end{array}$ \\
\hline $\mathrm{K}$ & & + & & $2779 \times 200 \mathrm{~m}$ & $3524 \times 200 \mathrm{~m}$ \\
\hline
\end{tabular}

NVD $=$ New vessels on the disc; NVE $=$ New vessels elsewhere; $(\mathrm{R})=$ Rodenstock panfunduscope lens; $\mathrm{m}=$ microns.
Table III. Reasons for referral of patients in Table II

\begin{tabular}{|c|c|}
\hline Patient & Reason for referral to Committee \\
\hline $\mathrm{C}$ & One para-macular congruent static miss due to focal laser. \\
\hline D & One peripheral congruent static miss. \\
\hline $\mathrm{E}$ & $\begin{array}{l}\text { Right rubeotic glaucoma on presentation causing severe } \\
\text { field loss right eye. Referral therefore on scotomas and } \\
\text { marked field constriction left eye. }\end{array}$ \\
\hline $\mathrm{F}$ & Bilateral superior field constriction. \\
\hline G & $\begin{array}{l}\text { Right homonymous hemianopia from cerebro-vascular } \\
\text { accident. Hemifield constriction left eye. }\end{array}$ \\
\hline $\mathrm{H}$ & $\begin{array}{l}\text { Trauma to right eye causing severe field loss. Field } \\
\text { constriction left eye to within } 30^{\circ} \text { of fixation. }\end{array}$ \\
\hline I & $\begin{array}{l}\text { Bilateral severe field constriction to within } 20^{\circ} \text { of } \\
\text { fixation. }\end{array}$ \\
\hline $\mathbf{J}$ & $\begin{array}{l}\text { Severe field constriction right eye following laser to disc } \\
\text { new vessels. Referral therefore on two static misses left } \\
\text { eye. }\end{array}$ \\
\hline $\mathrm{K}$ & $\begin{array}{l}\text { Three congruent static misses due to bilateral para- } \\
\text { macular focal laser. }\end{array}$ \\
\hline
\end{tabular}

either eye and the panfunduscope or indirect laser had not been used.

The remaining nine patients treated with laser had their fields assessed by the CVSC. Details of their treatment are shown in Table II. Reasons for referral to the CVSC are shown in Table III. He considered that he would recommend a limited term licence in six cases, one would be a definite fail (case I) and another case (case E) would require further consideration but would probably pass. Some important points may be illustrated by examination of some of these cases:

Patient $\mathrm{C}$ had one paracentral congruent static miss corresponding to an area of confluent burns above the fovea in both eyes (Figs. 1 and 2).

Patient $\mathrm{D}$ again had only one congruent static miss but had multiple misses in the nasal field of each eye following 500 micron burns to the temporal retinae (Fig. 1).

Patient I had 2500 burns at the 400 micron setting delivered to each eye with the panfunduscope lens. This

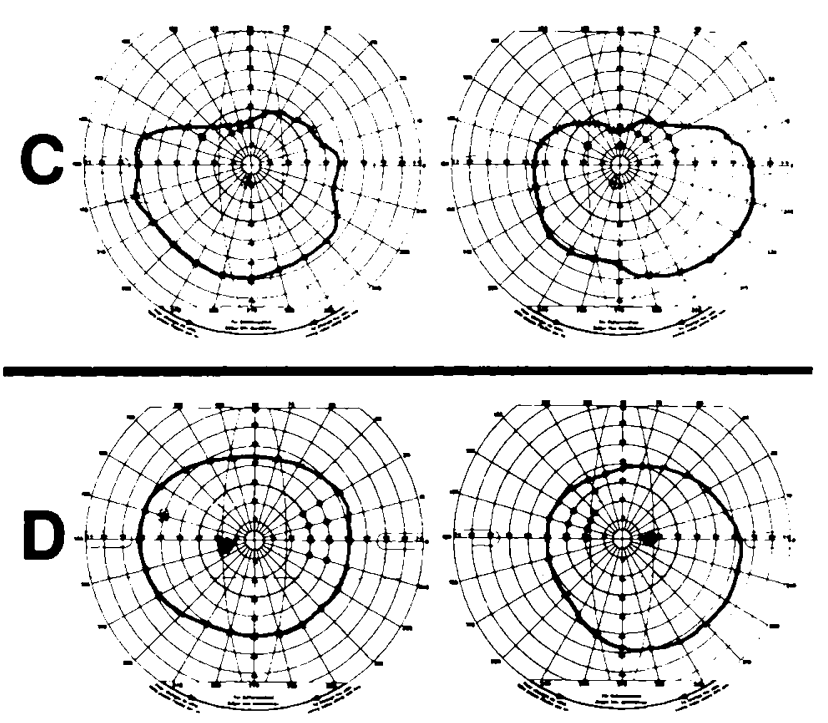

Fig. 1. Visual fields of patients $C$ and D. (All fields show kinetic isopter to III4e target on the Goldmann perimeter. Missed static points are indicated by spots, the patients' $R$ fields are on the right.) 


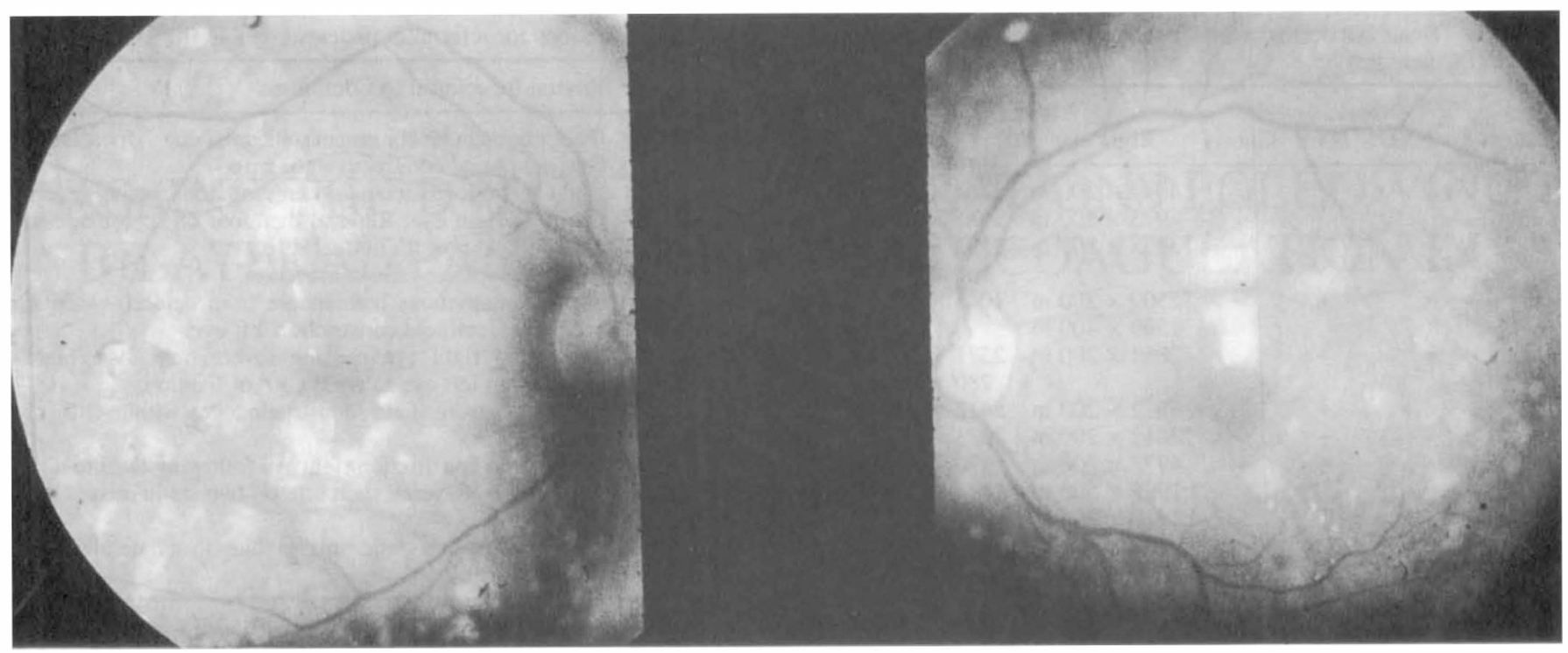

Fig. 2. Fundus photographs of patient $C$ showing bilateral paracentral confluent burns.

lens increases the burn diameter to 650 microns $^{8}$ and peripheral constriction was marked in both eyes (Fig. 3).

Patient J had direct treatment to new vessels on the disc of the right eye which had continued to bleed following PRP. The left eye received PRP with 3500 burns, $30 \%$ of these at the 500 micron setting (Fig. 3).

Some additional important points can be illustrated by examination of some of those to record a clear pass:

Patient L was fortunate not to have any congruent misses (Fig. 4) following PRP with 500 micron burns in the right eye and indirect laser in the left eye.

Despite the left eye having had 150 burns at the 500 micron setting, with typical scotoma production, patient M passed on just his right eye which had 3238 burns, none larger than 300 microns, for disc and peripheral new vessels (Fig. 4).

The 500 micron burns delivered to patient $\mathrm{R}$ were restricted to superior and inferior peripheral retina thus sparing the driving field (Fig. 5).
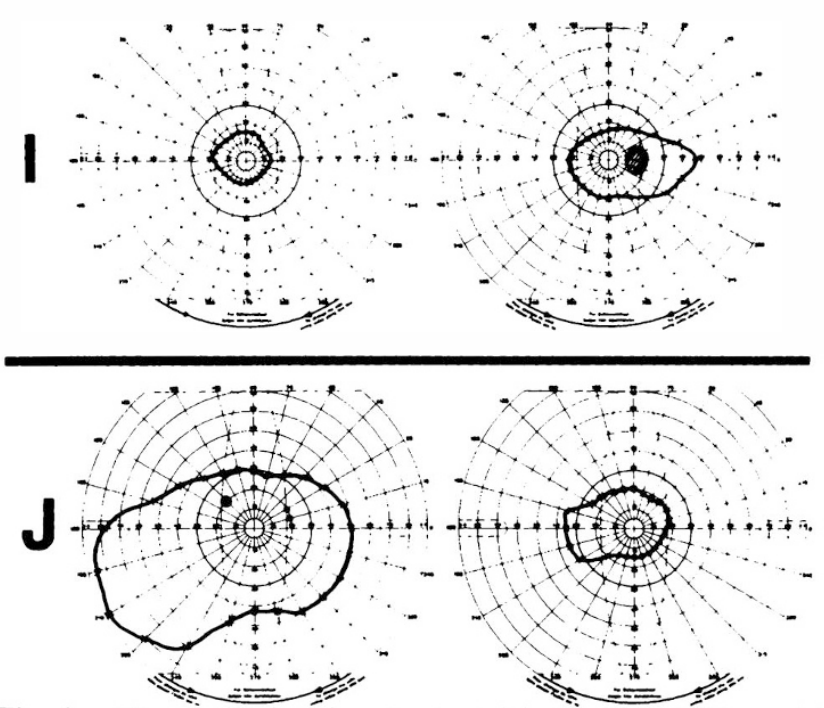

Fig. 3. Visual fields of patients I (deemed to fail) and $J$ (deemed to pass the DVLC field test)
We demonstrated a significant association between total burn area and field loss ( $p=0.027$ by Spearman's Rank Correlation Coefficient); a scattergram of burn area versus field loss within the DVLC field area is shown in Fig. 6.

\section{DISCUSSION}

A recent report has indicated that, despite passing the number plate test, $80 \%$ of patients who have had bilateral PRP (presumably with 500 micron burns) for proliferative diabetic retinopathy will fail the current DVLC field test. ${ }^{9}$ Our study, in which the predominant laser spot size used was 300 microns or less, indicates that successful photocoagulation in certain patients carries a high chance of being permitted to retain a private driving licence.

A number of our cases demonstrated static misses on field testing in association with the use of large laser spot
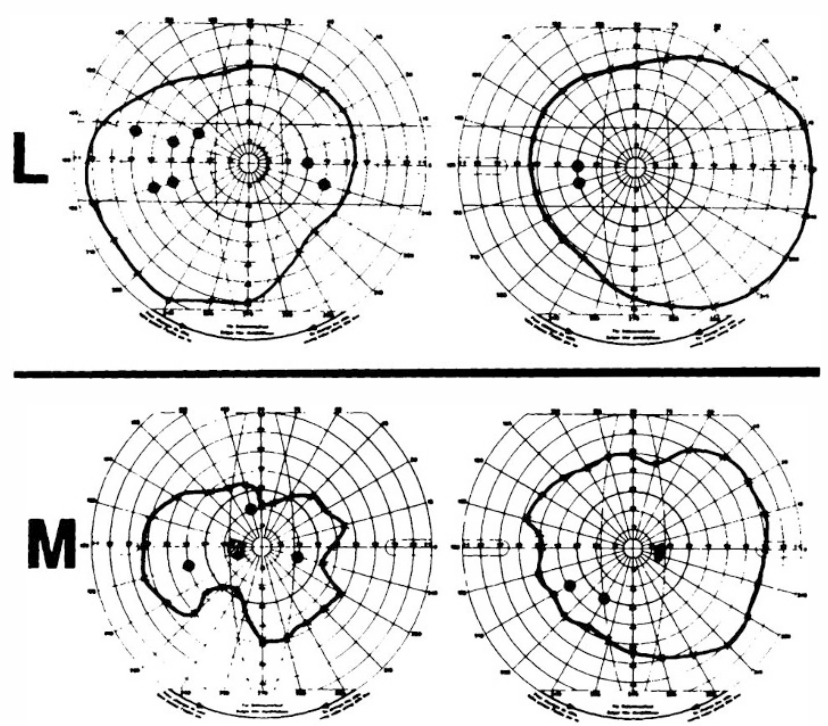

Fig. 4. Visual fields of selected patients who demonstrated clear passes on the DVLC field test despite individual eyes possessing scotomas. 


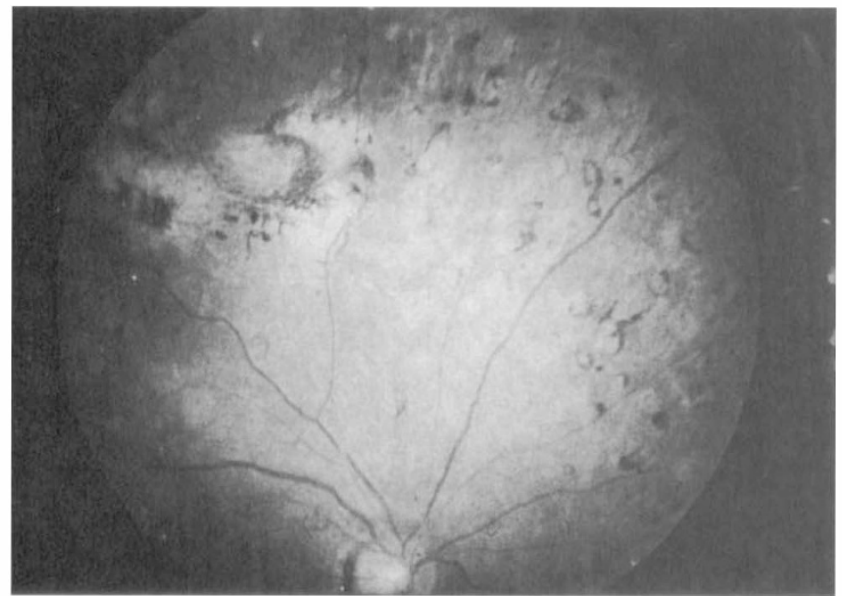

Fig. 5. Fundus photograph of right eye of patient $R$ showing larger burns not encroaching on arcades or disc.

sizes. The $4 \mathrm{~mm}$ target on the Goldmann perimeter subtends an angle of $0.7^{\circ}$ at the nodal point of the eye. This produces a 210 micron diameter spot on the retina of an eye of average axial length (Appendix 1). A 500 micron laser burn will eclipse the DVLC target, which is approximately the same size as a 200 micron burn.

Laser spot area is proportional to the square of the radius. Therefore it is difficult to separate the effect of large spot size from the effect of increasing total burn area statistically. Our subject group was far too small to detect such a statistical association while controlling for the very powerful relationship between burn size and total burn area. Based on the results of our study, we estimate the required sample size to be approximately 600 patients.

An as yet unquantifiable factor affecting burn size is the expansion of laser burns after application. ${ }^{10}$ This probably relates to burn uptake (dependent on wavelength, power applied and absorption variation in individual eyes), and

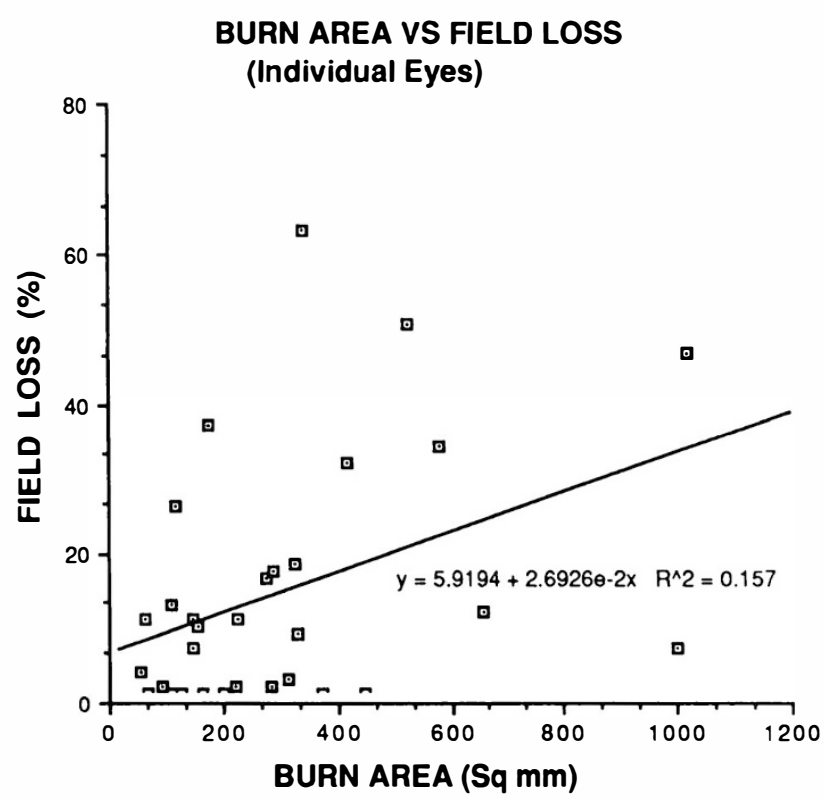

Fig. 6. Scattergram of burn area (calculated from treatment details) versus field loss (proportion of static points missed per eye within DVLC field zone expressed as a percentage). burn circumference rather than burn area, since it is from the burn margin that such expansion occurs.

Field loss induced by treating diabetic retinopathy with photocoagulation may be due to a number of mechanisms. ${ }^{11}$ Laser burns produce scotomas due to outer segment destruction, and nerve fibre bundle defects occur from thermal damage to the overlying nerve fibre layer (this is particularly likely if larger intraretinal vessels are hit by the laser beam). Secondary damage due to disorganisation occurs following thermal damage to smaller vessels and laser adjacent to the disc may cause thermal damage to the optic nerve. For a given laser power, all the above mechanisms are more likely if larger retinal burn sizes are used. In addition it should be remembered that the ischaemic process per se can produce scotomas, from either retinal or optic nerve hypoperfusion.

As screening for retinopathy becomes more common, patients with pre-proliferative retinopathy or early new vessel formation will be referred in larger numbers for management by ophthalmologists. The fear of inducing field loss by panphotocoagulation may deter some surgeons from treatment when loss of acuity in the short term seems remote.

The recent Early Treatment Diabetic Retinopathy Study report has confirmed that scatter PRP with 500 micron burns significantly reduces the risk of developing severe visual loss, even in eyes without disc new vessels but warns that field loss is common. ${ }^{12}$

None of the patients in our study with peripheral new vessels who were treated with small burn therapy in the absence of disc vessels had to be referred to the CVSC. This indicates that patients undergoing early treatment with smaller burns have a very low risk of losing their right to drive.

We have demonstrated that adequate PRP with 200 micron burns induces neovascular regression in many patients and is compatible with passing the DVLC field regulations. The use of larger burns of 500 micron size and above appears to reduce the chance of passing by increasing total burn area. and also by increasing the probability of static test scotomata from each burn.

As a result of our study we present the following guidelines for panphotocoagulation of proliferative and severe preproliferative diabetic retinopathy in patients requiring a United Kingdom driving licence:

(1) Use small burns, preferably no larger than 200 micron real size, avoiding major vessels and retina within the temporal arcades. Between 3000 and 3500 carefully applied burns induces regression in all but severe cases.

(2) Beware of confluent treatment particularly in maculopathy.

(3) Remember that the panfunduscope and similar lenses magnify the laser burn size.

(4) The use of the indirect laser or the Xenon coagulator should be reserved for recalcitrant cases as extensive peripheral constriction and/or scotomas are common.

(5) Preservation of central vision is, however, the paramount aim, and sufficient treatment should be applied to 


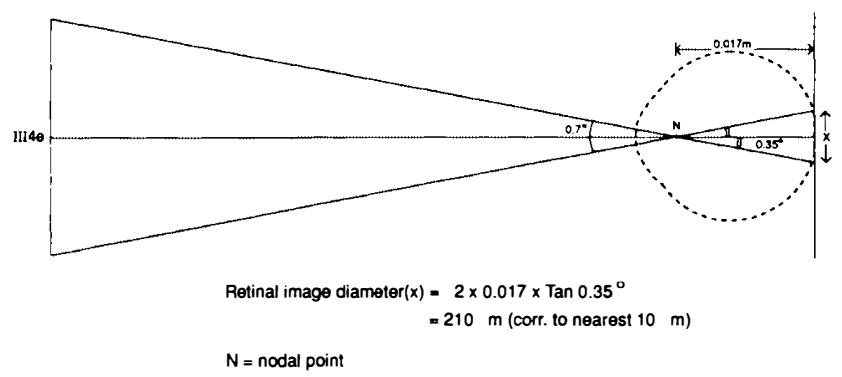

Appendix. The DVLC target corresponds to a 210 micron diameter image on the retina of an eye of average axial length.

induce neovascular regression. If additional photocoagulation is required apply it initially to the superior and inferior retina so that it falls at least $20^{\circ}$ from the midline horizontal, thus sparing the visual field considered most valuable for driving.

The authors thank the Chairman of the Visual Standards Committee of the College of Ophthalmologists for his co-operation in this study and Mr P. Pawson (research optometrist) who performed the visual fields.

Key words: Diabetes, Driving, Laser, Photocoagulation, Retinopathy, Visual field.

\section{REFERENCES}

1. Little HL: Treatment of proliferative diabetic retinopathy. Long-term results of argon laser photocoagulation. Ophthalmology 1985, 92: 279-83.

2. Blankenship GW: Fifteen-year argon laser and xenon photocoagulation results of Bascon Palmer Eye Institute's patients participating in the Diabetic Retinopathy Study. Ophthalmology 1991, 98: 125-8.

3. Atlas of Clinical Ophthalmology ed. Spalton DJ, Hitchings RA, Hunter PA. 1984 Churchill Livingstone.

4. Drasdo N, Haggerty CM: A comparison of the British number plate and Snellen vision tests for car drivers. Transport and Road Research Laboratory, Crowthorne LF 676.

5. Driver's fields agreed College of Ophthalmologists; College News Spring 1991.

6. Frank RN: Visual fields and electroretinography following extensive photocoagulation. Arch Ophthalmol 1975, 93: 591-8.

7. Hamilton AM, Townsend C, Khoury D, Gould E, Blach RK: Xenon arc and laser photocoagulation in the treatment of diabetic disc neovascularisation. Part 1. Effect on disc vessels, visual fields and visual acuity. Trans Ophthalmol Soc UK 1981, 101: 87-92.

8. Mainster MA, Crossman JL, Erickson PJ, Heacock GL: Retinal laser lenses: magnification, spot size and field of view. Br J Ophthalmol 1990, 74: 177-9.

9. Williamson TH, George N, Flanagan DW, Norris V, Blamires $\mathrm{T}$ : Driving standard visual fields in diabetic patients after panretinal laser photocoagulation. Vision in Vehicles 111. North-Holland 1991, pp. 265-72.

10. Schatz H, et al.: Progressive enlargement of laser scars following grid laser photocoagulation for diffuse diabetic macular oedema. Arch Ophthalmol 1991, 109: 1549-51.

11. Marshall J, Bird AC: A comparative histopathological study of argon and krypton laser irradiations of the human retina. Br J Ophthalmol 1979, 63: 657-68.

12. Early Treatment Diabetic Retinopathy Study Research Group. Early photocoagulation for diabetic retinopathy. ETDRS Report Number 9. Ophthalmology 1991, 98: 766-85. 